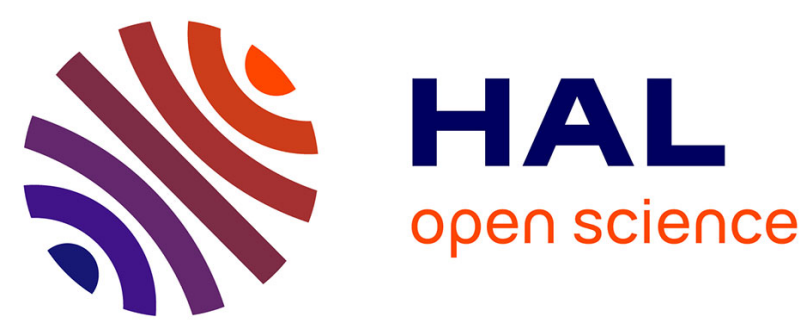

\title{
Mobile Computing is not Always Advantageous: Lessons Learned from a Real-World Case Study in a Hospital
} Andreas Holzinger, Bettina Sommerauer, Peter Spitzer, Simon Juric, Borut Zalik, Matjaz Debevc, Chantal Lidynia, André Calero Valdez, Carsten Roecker, Martina Ziefle

\section{To cite this version:}

Andreas Holzinger, Bettina Sommerauer, Peter Spitzer, Simon Juric, Borut Zalik, et al.. Mobile Computing is not Always Advantageous: Lessons Learned from a Real-World Case Study in a Hospital. International Cross-Domain Conference and Workshop on Availability, Reliability, and Security (CDARES), Sep 2014, Fribourg, Switzerland. pp.110-123, 10.1007/978-3-319-10975-6_8 . hal-01403989

\section{HAL Id: hal-01403989 \\ https://hal.inria.fr/hal-01403989}

Submitted on 28 Nov 2016

HAL is a multi-disciplinary open access archive for the deposit and dissemination of scientific research documents, whether they are published or not. The documents may come from teaching and research institutions in France or abroad, or from public or private research centers.
L'archive ouverte pluridisciplinaire HAL, est destinée au dépôt et à la diffusion de documents scientifiques de niveau recherche, publiés ou non, émanant des établissements d'enseignement et de recherche français ou étrangers, des laboratoires publics ou privés. 


\title{
Mobile Computing is not Always Advantageous: Lessons Learned from a Real-World Case Study in a Hospital
}

\author{
Andreas Holzinger ${ }^{1}$, Bettina Sommerauer ${ }^{1}$, Peter Spitzer ${ }^{2}$, \\ Simon Juric ${ }^{3}$, Borut Zalik ${ }^{3}$, Matjaz Debevc ${ }^{3}$ \\ Chantal Lidynia ${ }^{4}$, André Calero Valdez ${ }^{4}$, Carsten Roecker ${ }^{1,4}$, Martina Ziefle ${ }^{4}$ \\ ${ }^{1}$ Research Unit Human-Computer Interaction, \\ Institute for Medical Informatics, Statistics and Documentation, Medical University Graz, \\ $<$ a.holzinger , b. sommerauer, c. roecker>@hci4all.at \\ ${ }^{2}$ Department of Pediadric Surgery, Graz University Hospital \\ peter.spitzer@klinikum-graz.at \\ ${ }^{3}$ Faculty of Electrical Engineering and Computer Science, University of Maribor \\ <simon.juric, borut.zalik,matjaz.debevc>@um.si \\ ${ }^{4}$ Human-Computer Interaction Center, RWTH Aachen University, Germany \\ <lidynia, calero-valdez, Ziefle>@comm.rwth-aachen.de
}

\begin{abstract}
The use of mobile computing is expanding dramatically in recent years and trends indicate that "the future is mobile". Nowadays, mobile computing plays an increasingly important role in the biomedical domain, and particularly in hospitals. The benefits of using mobile devices in hospitals are no longer disputed and many applications for medical care are already available. Many studies have proven that mobile technologies can bring various benefits for enhancing information management in the hospital. But is mobility a solution for every problem?

In this paper, we will demonstrate that mobility is not always an advantage. On the basis of a field study at the pediatric surgery of a large University Hospital, we have learned within a two-year long mobile computing project, that mobile devices have indeed many disadvantages, particularly in stressful and hectic situations and we conclude that mobile computing is not always advantageous.
\end{abstract}

Keywords: Mobile computing, real-world, user experience, hospital computing, medical informatics

\section{Introduction and Motivation for Research}

As the role of technology has grown smart phones and tablet computers ensure that staying connected 24/7 is not only possible but often expected, accelerating the hype in mobile computing [1]. Since the advent of personal digital assistants, mobile devices (e.g., smart phones and tablet computers) have also been widely adopted by medical professionals. Especially for young health professionals, these devices are 
quickly becoming one of the main tools for accessing medical information, following the general trend: according to [2], 63\% of all internet users get access to the World Wide Web via portable devices, e.g., laptop, tablet, or smart phone - with an increasing tendency; $88 \%$ of people between 16 and 24 years of age use portable devices for internet access instead of their desktop computers at home and/or at work. We may say that mobility has become an integral part of everything we do in our daily lives. With the introduction of newer and more powerful smart phones and tablets, mobile users have easy and immediate access to information everywhere and at any time, a recent discussion of the state-of-the-art can be found here [3].

There has been a tremendous surge in the number of available mobile health technologies around the world [4]. According to a recent study [5], already in 2009 about two out of three people worldwide owned a mobile phone. A 2011 global survey of 114 nations [6], carried out by the World Health Organization, found that mobile health initiatives have been established in many countries.

The most common purpose was the creation of health call centers that respond to patient inquiries. This was followed by the use of SMS for appointment reminders, the use of telemedicine, the access of patient records, measuring treatment compliance, the promotion of health awareness by conducting health surveys, patient monitoring, and creating a decision support system for physicians (see Fig. 1).

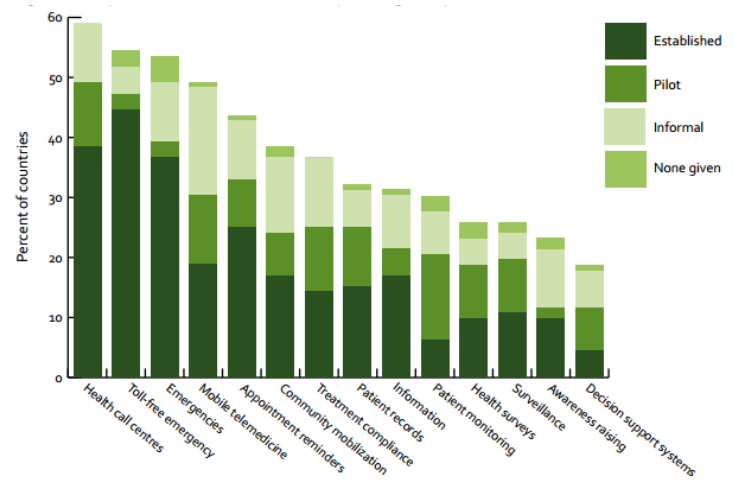

Fig. 1. Overview of mobile health applications worldwide in regard to type of service [5]

Based on previous work and based on the success story of a previous project [7] the primary goal of our project was to provide the benefits of such portable devices into the specific environment of emergency medicine: Every patient who requires medical care at the Department of Pediatric Surgery in Graz has to be recorded at the local medical information system (openMedocs), based on a SAP healthcare solution. In this system every patient has his own record with a patient report for each accident, including a collection of accident data (e.g. location, circumstances etc.). As this is a burdensome additional work for the clinicians, the idea was that the patients or their chaperons fill in this data. As an added bonus, this would also involve the patient at an even earlier stage of the treatment process. Unless in cases of life-threatening injuries, patients are always required to spend some time waiting until a doctor can see them. Then they need to fill out forms and answer questions of a doctor or nurse 
who needs to write down the answers before the actual medical treatment can begin. This seems like a huge expenditure of time and our goal was to use the waiting period more efficiently and thereby free the doctors of work, so they can concentrate on the medical side of their profession, instead of them gathering data As an added bonus, this would also involve the patient at an even earlier stage of the treatment process. In the pigment lesion clinic this works in daily routine with excellent results [7].

\section{Background and Related Work}

Today, the health care industry is booming, which includes the need of handling large quantities of data [8], consequently, the necessity of computerized systems in the medical sector is indisputable, and much previous work is reporting on a multitude of benefits by the application of mobile computing in medicine and health care (see e.g. $[6,9-12]$.

\subsection{Mobile Devices}

Mobile devices such as Smartphones with advanced performance properties and especially tablet computers use a touch screen as main interaction method. For this reason, the design of applications running on these devices is crucial for the success of both the application and the device and particularly multi-touch interaction poses a lot of challenges but also possibilities for the developer [13]. The acceptance of mobile devices depends above all on their usefulness and their usability [14]. When using such devices it is quite apparent that the limited space on their screens involves significant challenges to the developers and usability engineers [15], [16],[17]. For example, one study demonstrated that a touch-based mobile device can be used successfully within the healthcare context only if it has an appropriate design [18]. For this reason, the necessity of usability engineering methods [19] is meanwhile commonly acknowledged for the development of medical mobile devices, as several studies show [20], [21], [14]. Mobile devices for medical contexts must always be created with the end user in mind and pay attention to the end user's expertise with both the technology as well as the domain (context) of its use [22], [23], [24].

The specifics of mobile devices pose special challenges in design and usage when they are to be used for mobile questionnaires, especially as they include multiple questions to be answered. Although several studies have already targeted this subject, e.g., [25], [26], [27], [28] and some solutions have been developed, there are no known tutorials on how to best develop mobile questionnaires as of yet. However, a user experience evaluation has found that the four most important things to keep in mind when developing questionnaires for mobile devices are the small screen size, the data entry method and interaction style, the mobile context, and the chosen implementation for the questionnaire [29].

\subsection{Mobile Devices in Hospitals}

There are several studies and reviews about the implementation of mobile computing in hospitals, including [26], [30], [31], [32], [33], [34], to mention only a few. The 
study of [26], e.g., gives a comprehensive picture of how to integrate handheld devices into health care and the possible applications of PDAs. Previous studies have clearly shown that the users' information satisfaction resulting from the use of a mobile electronic medication administration record is significantly higher than that observed with the benchmark paper-based workflow, see [35], or [36].

\subsection{Touch and Gesture Inputs}

In recent years, the use of gestural interface technology has become much more frequent in mass consumer products, especially products such as the Apple iPhone or the Nintendo Wii videogame console; both can be regarded as pioneering examples of this technology. An ever increasing number of consumer electronics manufactures have developed gesture control elements and included this technology in a whole range of mobile electronic devices such as laptops, cell phones, PDAs, remote controls, navigation systems, and digital cameras. It is not surprising that there are studies about, for example, the Nintendo Wii Remote Controller and its use in the area of e-Teaching. One study shows the design and development of a low-cost demonstrator kit for the Wiimote [37]. It concludes that gestures can enhance the quality of learning processes for children by adding another layer to the instructional discourse. Communication is not restricted to verbal speech and language alone. One cornerstone of human interaction lies in non-verbal communication, parts of which are gestures that are used to complement verbal messages.

Other studies indicate that touch interfaces and their use are much more natural to users than other input devices such as mouse, touchpad or trackball [38], [39], [40]. An added benefit of touch-screen devices is the easier maintenance in terms of cleanness and hygiene. A flat screen is much simpler to swipe clean and disinfect than the movable parts of the other input devices, an important aspect for the use in a hospital.

\section{$3 \quad$ Experiment}

The field of application for the questionnaire developed by us was the emergency department of the pediatric surgery in Graz. A mobile questionnaire can add value by replacing handwritten documentation, thereby providing more accurate and complete documentation with less risk of transcription errors or legibility issues. For this work, not all the features of a tablet PC were utilized, because only a single application, namely our questionnaire, was run on the device.

In this specific case, we could not draw on literature or previous studies about the best screen size, the ideal weight, or the optimal battery life for effective handling in a hospital scenario. There are no such sources yet. The only way to come to a definite solution as to which device is the best for the use in such an environment is to test possible candidates in real life. We began our test phase with an iPad as input device.

For this work, the handling, the practicability and the ease of use was most important. Especially, as an emergency department is a place of urgency and hectic activity, meaning cumbersome equipment or difficult or hard to use software defeat the purpose of easing the workload and providing quick and accurate information. 
Additionally, we designed this application with the idea that filling out the questionnaire should also provide the patients with a simple task to calm their nerves and help bridge the time spent waiting for the doctor to see them. Due to the fact that it is the pediatric surgery, also elements of play were under consideration, to keep the motivation for the input of the data.

\subsection{System Architecture}

For the experiment, a web application for tablet computers was developed. To understand the whole system, it is important to have a short look at the technical environment. In order to display heterogeneous IT-systems of numerous hospitals, a system was developed by the Styrian healthcare organization (KAGes) and governing body of Styrian hospitals. This countrywide hospital information system (HIS), called openMedocs, is a customized software product designed by the commercial company SAP. The core of openMedocs is the electronic patient record (EPR) system which is used for patient management. All documents and patient data are stored in this system.

Because very sensitive information about every patient is stored here, there has to be high data security, guaranteed by strict privacy policies [41], [42]. Due to this fact, the questionnaire for the patient reports cannot be easily integrated in Medocs. Consequently, the questionnaire is designed and developed completely autonomously.

Therefore, the questionnaire will be a stand-alone system which operates only on the frontend side. For that reason, all necessary data for the development of the questionnaire, i.e., the questions, the answers, the structure, and the logical interconnection, are stored locally on the tablet.

\subsection{User Interaction}

The user interface of the tablet application was designed with the future users (parents or guardians and children) in mind. The visuals are based on the corporate identity of the clinic called "Bärenburg" (German for "bears castle", which is a child safety house, built as a center for injury prevention adjacent to the pediatric surgery) and have a child-friendly user interface with large text buttons (see Fig. 2). The interaction with the system is based on a linear sequence of questions that need to be answered one after another. The user fills in the questionnaire to record the individual accident data and then finishes the data input. 


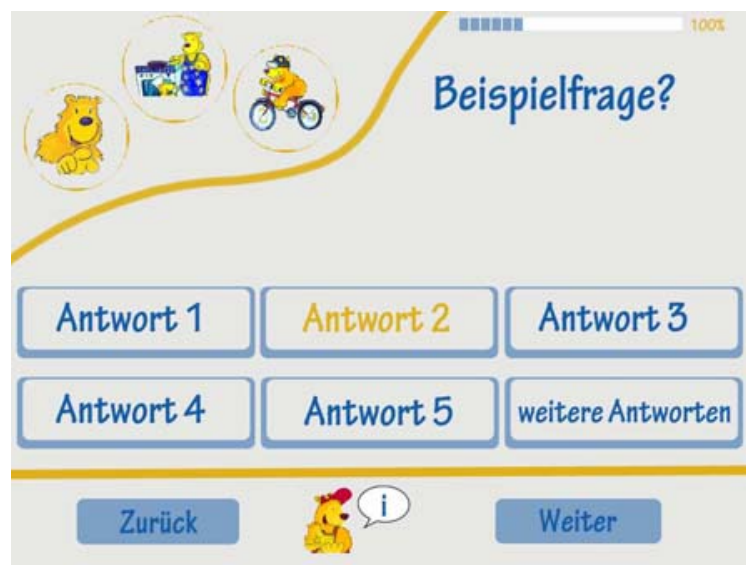

Fig. 2. Questionnaire screen shot of one version of an early prototype

After all the questions have been answered, the completed questionnaire is transferred into Medocs, the hospital wide enterprise hospital information system. The integration of the patient data into the hospital information system is based on an existing system from cancer research [7]. Therefore, the same XML interface as the technical protocol can be used so that the data collected from the questionnaire can be transferred directly into the Medocs-System via remote function call. The XML file contains all the patient's answer as well as the corresponding questions. All the obtained information is then stored in Medocs and the medical personnel, i.e., doctors and nurses, have access to the data of each patient at any given time and any place in the clinical workplace (see system architecture in Fig. 3).

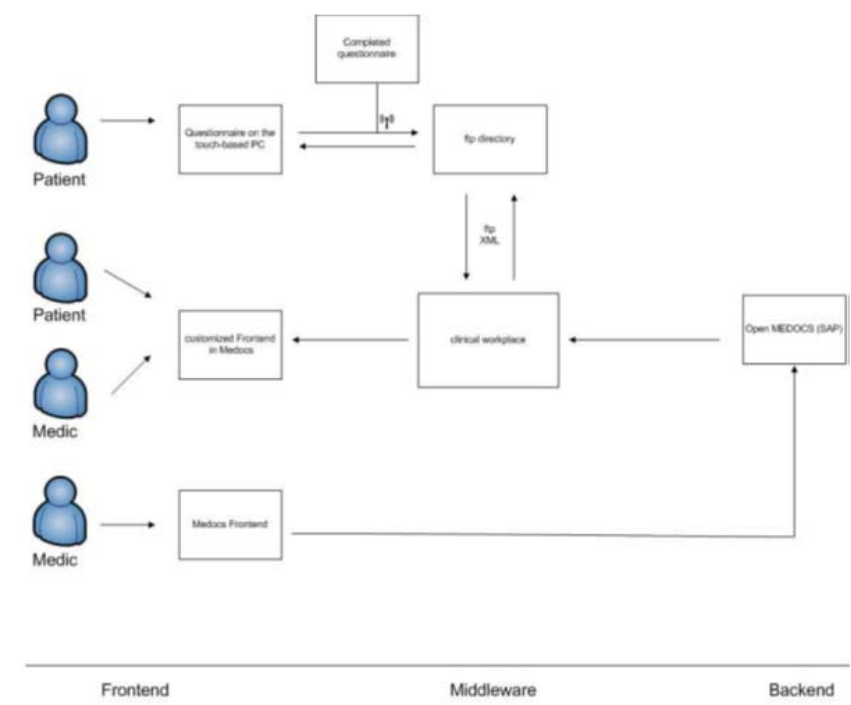

Fig. 3. System architecture of the Medocs system with our tablet solution 


\subsection{Test Users}

As the application is used in a pediatric surgery, the target test users of this questionnaire are young patients and their escorts. With both injured children and their chaperons as users of this interface there cannot be any restrictions as to age or computer experience. All users were inexperienced with the system in the test.

The test subjects were acquired from patients visiting the pediatric surgery in Graz. The test was conducted on three days per week and but only with patients who were there for a second checkup. This was done to avoid the stressful situation of the initial visit to the hospital. Nevertheless, only about $10 \%$ of the persons approached agreed to participate in the experimental procedure. A total of 58 patients tested the system in the real-world. In this study, the test users were both adolescents and parents.

\subsection{Collecting Results and Procedure}

The field of application for the developed questionnaire is the emergency department. Here, the medical personnel needs complete, accurate, and quick information about the patient and the circumstances that brought them there. An electronic questionnaire on a mobile device can provide this by preventing the possibility of skipping questions and also uploading the information into the hospital system, thereby enabling the doctors or nurses to instantly access and, if necessary, edit the data.

For this work, only the handling and easy practicability were studied. The system was tested in two trials. The first trial was used to identify possible usability problems with the questionnaire tool. For this purpose, the system usability scale (SUS) was used. To avoid cross-over effects of device usability and usage context, the first test was conducted with demo-data (gathered from a database of previous examinations) but real patients that came into the clinic for additional checkups. The results from the initial trial were then used to restructure the survey tool before the real life test. This real life test was also conducted in the pediatric surgery but with current cases. An iPad was handed to the patients prior to the doctor's visit. This was not only done to collect data but also to bridge the waiting period of patients. Results were established as qualitative data. Additionally, the SUS was measured again to ensure the changes to the application from the first trial were actually improving the system.

No task set was defined for the real test. It was necessary to collect actual patient data of real cases to test the usability of the system accurately.

\section{$4 \quad$ Results}

The improvement of the prototype after the first trial was in general successful. Before the improvement, the questionnaire tool showed a SUS score of $54.4 \%$. Scores under $60 \%$ represent major usability issues according to [Fehler! Verweisquelle konnte nicht gefunden werden.]. In the following iteration of the test, with an improved version, the score increased to $72 \%$, which is a considerable improvement but still below the acceptable benchmark of approximately $80 \%$. The individual results of the SUS can be seen in Fig. 4. 
While most of the usability items yielded better results in the real test, two items dropped notably below the initial assessment of the pilot test. The first one, and also the strongest perceived hurdle of the mobile questionnaire, was the use of the system without assistance from an expert (question 4 - "I believe I require help when using the system."). This was followed by the assessment of the overall complexity of the topic at hand (question 6 - "I find answering these questions hard.").

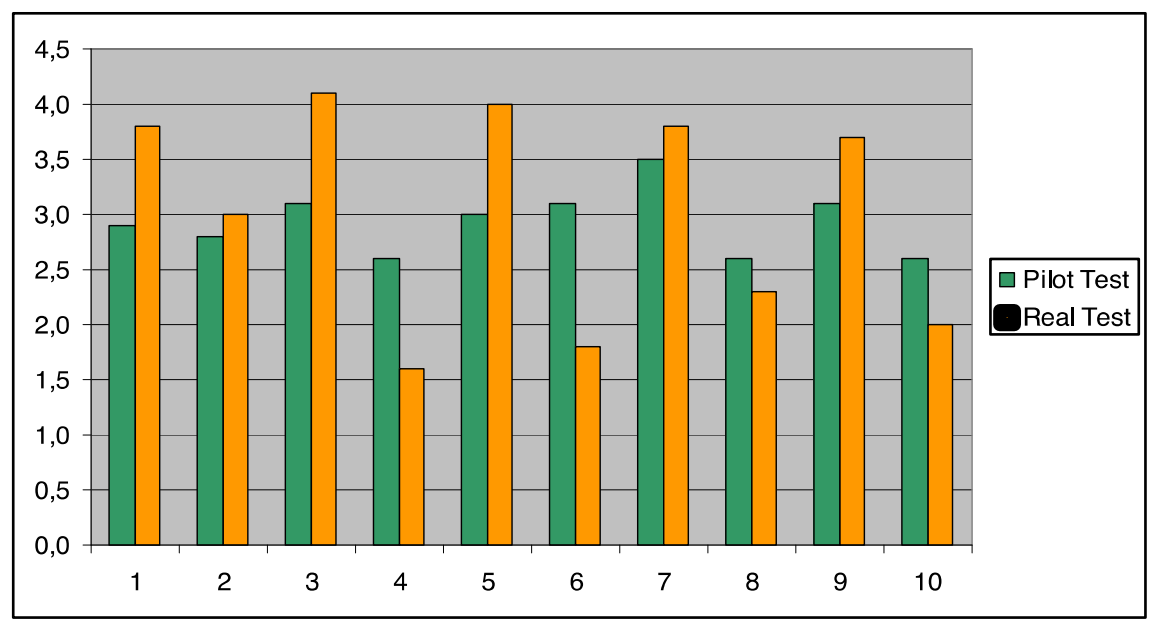

Fig. 4. SUS scores for the pilot and the real test for the questionnaire tool

Beyond the quantitative results, qualitative observations of the whole procedure were recorded. The following paragraphs report the findings from these observations.

\subsection{Qualitative Observations}

During the trial, several observations have been made about the general usage as well as the practicability of the mobile device in the environment of a hospital's emergency room. Due to agitation, anxiety, confusion, the continuous arrival of new patients as well as departure of already treated patients, the mobile solution showed several disadvantages during the experimental testing phase in real life.

\section{Keeping track of tablets and incidental theft.}

Because new patients continuously arrive in the hospital, waiting patients are called into the doctor's office, or patients leave the emergency room after the treatment, it is very difficult to keep track of the distributed tablet computers. Although the secretary or nurse can hand the device to a particular patient, it is not impossible for another patient to take over the device after the initial patient has completed the questionnaire, and begin a new data entry session. The resulting constant change of persons handling 
the device and people moving around also makes the accidental removal of a tablet from the waiting room easier, either by absentmindedly bagging it or by taking it into another room of the hospital. Keeping track of the tablets is further challenged by the fact that many people bring a tablet or mobile device of their own to use while waiting in the anteroom or reception area.

\section{Falling down.}

A very big problem of the mobile solution is the possibility of the device falling down or being dropped. The tablet PC will be used in the department of pediatric surgery, a very hectic and chaotic environment. There are many children who cannot remain in their seats or fidget restlessly, particularly in a stressful and more than likely unfamiliar environment like a clinic. That plus medical personnel rushing between rooms due to emergencies or children running around increase the risk of a device being damaged by a drop to the ground.

\section{Getting wet.}

Due to the chaotic environment it is also easily possible that liquids might be spilled on the device. Especially in the pediatric hospital, there are always drinks present, mainly to soothe the young patients. Within the hectic environment and stressful situation of a visit to the emergency room, the frequency of the drinks being dropped or spilled is quite high. Additionally, hospitals, and in this case especially surgical or emergency departments, do have handle and deal with larger quantities of either liquid medication, e.g., infusion bags or bottles, or even bodily fluids, e.g., blood from an open wound. All these factors carry a high risk of the portable device being damaged by liquids.

\section{Usage context.}

The flurry of activities and worry of the guardians and patients was a major obstacle when handling the device. In a stressful situation like the aftermath of an accident, participants were not able to concentrate on using a touch screen-based questionnaire tool. Hurting kids crying and wanting to be soothed presented a major hindrance for using the device. Additionally, as soon as the doctor called in a patient, the questionnaires were abandoned and left incomplete as patients rushed into the doctor's office.

Another disadvantage in this usage context is the small display size. With the application being designed mainly for children, i.e., using a larger font size, pictures, and big buttons, the presented text had to be short to avoid scrolling or overloading the screen. For an initial anamnesis and case history given by the patient, as was the idea behind this project, mobility is not a necessity in the end. 


\section{Discussion}

Because in primary care, children, young people, and especially their guardians and chaperons are always under pressure, highly stressed, or even just concerned, we have decided to test our prototype only on patients who have come into the pediatric surgery for follow-up examinations. To advise children and their parents of the questionnaire, and to minimize inhibitions against this new system in the test run, they were assisted by a staff member of the Centre for Accident Research, in our case a pediatric nurse. Although this employee actively went to the patients and their parents and asked them to complete the questionnaire, only 10 percent actually did so.

In order to provide a complete collection of accident data and to permit the attending doctors to know how the accident happened shortly before the actual treatment, it has to be ensured that each patient fills out the questionnaire in the waiting room of the emergency department as completely as possible and to the best of their knowledge. However, as we have seen in the evaluation, both the children and young patients themselves but especially the accompanying persons, mostly parents, are too anxious and panicked to ultimately do so.

\section{Conclusion}

With the increasing spread and general usefulness of mobile devices, we had the idea to employ them in the context of initial patient assessment in an emergency room. Here, they were meant to gather important information about the patient and the accident as well as try and help shorten the waiting time by distracting the patients and their attendants.Medical doctors and nurses work in an environment that requires high mobility. The usefulness of handheld computers in the field of medicine is respected, even among patients. Consequently, it is not astonishing that mobile devices are already frequently used in medical care scenarios. Therefore, the new interface developed for this work should be implemented on a tablet computer. Inspiration for this project came from the successful implementation of a mobile solution in the dermatology clinic in Graz, a project in which a method was implemented that collects data by patients filling out a questionnaire on a touchscreen device. For this work, we then developed mock-ups for a mobile device and tested the idea in real life scenario. During the test phase, we found that in this case scenario a mobile solution is not the best option. These results support the opinion of the medical staff, confronted on a daily basis with the hectic environment of the ER, who also advised against a mobile solution. For future applications of the questionnaire tool, a kiosk-based solution should be implemented, allowing the guardian to hold their child while clicking on the touch-screen solution (see Figure 5). The initial observations show that a non-mobile solution in this context is far superior to a mobile device. Furthermore, a standardized system can improve the data quality in patient records, but it must not necessarily be done by the patient alone; a cooperative usage of a questionnaire system with a doctor is feasible.

We can conclude, that in the hectic and turbulent environment with crying children around, a mobile solution is neither useful nor usable and poses a lot of unsolvable problems: mobile computing is not always an advantage in the hospital-world. 


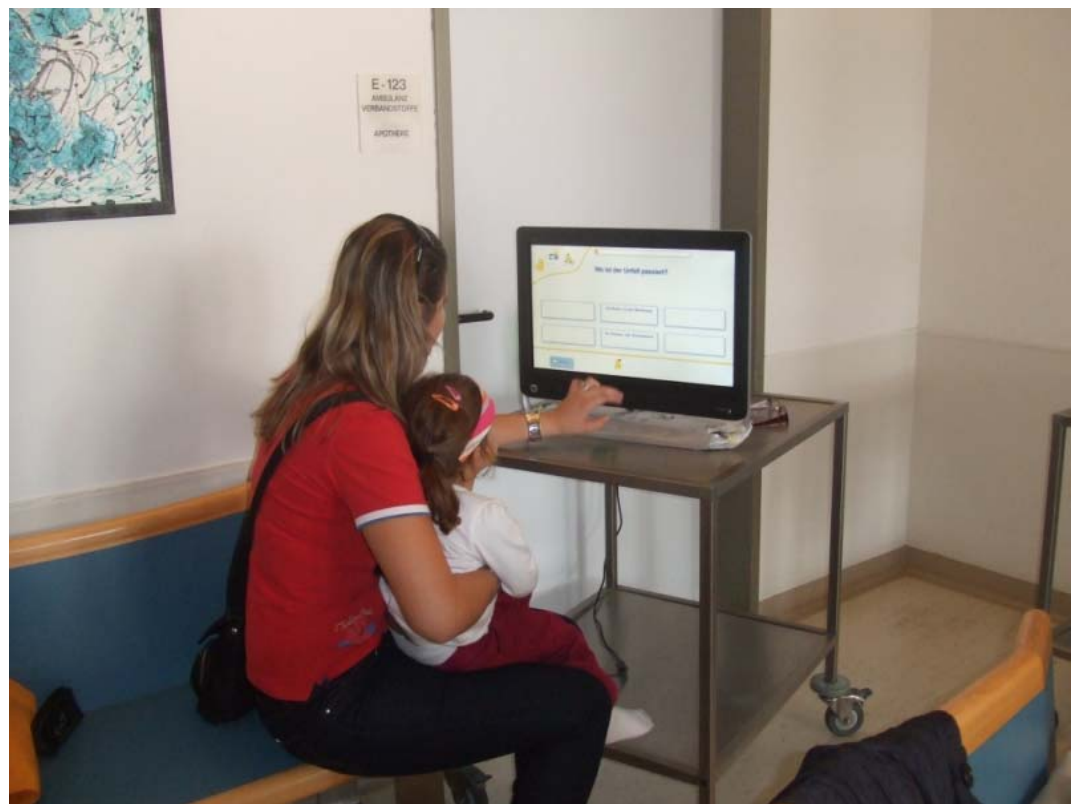

Fig. 5. Kiosk-based solution of the questionnaire tool. A mother and her child use the system in the waiting room

\section{$7 \quad$ Limitations}

The validity of the experiment can be challenged from a methodological and procedural angle. First comparing the results of a second return with an initial visit to the hospital is questionable. The idea to test in the second return of the patient came up, when patients were completely unwilling to take part in the study during the initial stressful visit after an accident. Not all patients necessary come back for a second visit, rendering the device non-useful for those who don't. Having an assistant direct you to a device but not assist you might also lead to patients aborting the test. In general one must assume that only patients (or chaperons) that felt comfortable using the device completed the trial. This might also lead to positively biased results in the evaluation. Nonetheless these biases strengthen the central statement of this paper rather than contradict it. No influence of the doctor's opinion of the device must be assumed, as usage was performed before meeting with a doctor.

Acknowledgements. We are grateful for the support of Graz University Hospital, particularly for the support of the Bärenburg and of all the medical professionals of the pediatric surgery team and technical support of the IT-Services department of the Styrian Hospital. We would also like to cordially thank all anonymous reviewers for their effort and insightful input on a previous version of this paper. 


\section{$8 \quad$ References}

1. Edmondson, J., Anderson, W., Gray, J., Loyall, J.P., Schmid, K., White, J.: NextGeneration Mobile Computing. IEEE Software 31(2), 44-47 (2014)

2. (last visited 14.05.2014), www.statistik.at

3. Röcker, C.: Smart Medical Services: A Discussion of State-of-The-Art Approaches. In: Proceedings of the International IEEE Conference on Machine Learning and Computing, pp. 26-28. (2011)

4. Röcker, C., Ziefle, M., Holzinger, A.: From Computer Innovation to Human Integration: Current Trends and Challenges for Pervasive HealthTechnologies. In: Holzinger, A., Ziefle, M., Röcker, C. (eds.) Pervasive Health, pp. 1-17. Springer London (2014)

5. Free, C., Phillips, G., Watson, L., Galli, L., Felix, L., Edwards, P., Patel, V., Haines, A.: The effectiveness of mobile-health technologies to improve health care service delivery processes: a systematic review and meta-analysis. PLoS medicine 10(1), e1001363 (2013)

6. Kay, M., Santos, J., Takane, M.: mHealth: New horizons for health through mobile technologies. World Health Organization (2011)

7. Holzinger, A., Kosec, P., Schwantzer, G., Debevc, M., Hofmann-Wellenhof, R., Frühauf, J.: Design and Development of a Mobile Computer Application to Reengineer Workflows in the Hospital and the Methodology to evaluate its Effectiveness. J. Biomed. Inform. 44(6), 968-977 (2011)

8. Holzinger, A., Dehmer, M., Jurisica, I.: Knowledge Discovery and interactive Data Mining in Bioinformatics - State-of-the-Art, future challenges and research directions. BMC Bioinformatics 15(Suppl 6), I1 (2014)

9. Waegemann, C.P.: mHealth: The Next Generation of Telemedicine? Telemedicine Journal and E-Health 16(1), 23-25 (2010)

10. Phillips, G., Felix, L., Galli, L., Patel, V., Edwards, P.: The effectiveness of M-health technologies for improving health and health services: a systematic review protocol. BMC Research Notes 3(1), 250 (2010)

11. Juric, S., Flis, V., Debevc, M., Holzinger, A., Zalik, B.: Towards a Low-Cost Mobile Subcutaneous Vein Detection Solution Using Near-Infrared Spectroscopy. The Scientific World Journal 2014(15 (2014)

12. B. Peischl, Ferk, M., Holzinger, A.: The Fine Art of User-centered Software Development on the example of Mobile Medical Apps (doi: 10.1007/s11219-014-92391). Softw. Qual. J. in print (2014)

13. Holzinger, A., Ofner, B., Dehmer, M.: Multi-touch Graph-Based Interaction for Knowledge Discovery on Mobile Devices: State-of-the-Art and Future Challenges. In: Holzinger, A., Jurisica, I. (eds.) Interactive Knowledge Discovery and Data Mining: State-of-the-Art and Future Challenges in Biomedical Informatics, Springer Lecture Notes in Computer Science LNCS 8401, pp. 241-254. Springer, Berlin, Heidelberg (2014)

14. Harrison, R., Flood, D., Duce, D.: Usability of mobile applications: literature review and rationale for a new usability model. Journal of Interaction Science 1(1), 1-16 (2013)

15. Calero-Valdez, A., Ziefle, M., Schroeder, U., Horstmann, A., Herding, D.: Task performance in mobile and ambient interfaces. Does size matter for usability of electronic diabetes assistants? Full paper at the (IEEE), in press. In: IEEE International Conference of the I-Society, pp. in press. (2010)

16. Oehl, M., Sutter, C., Ziefle, M.: Considerations on efficient touch interfaces-how display size influences the performance in an applied pointing task. Human interface and the management of information. Methods, techniques and tools in information design, pp. 136-143. Springer (2007) 
17. Holzinger, A., Errath, M.: Mobile computer Web-application design in medicine: some research based guidelines. Universal Access in the Information Society International Journal 6(1), 31-41 (2007)

18. Sax, C., Lawrence, E.: Tangible Information: Gestures for a Portable e-Nursing touch screen interface. In: e-Health Networking, Applications and Services, 2009. Healthcom 2009. 11th International Conference on, pp. 1-8. IEEE, (2009)

19. Holzinger, A.: Usability engineering methods for software developers. Communications of the ACM 48(1), 71-74 (2005)

20. Graham, M.J., Kubose, T.K., Jordan, D., Zhang, J., Johnson, T.R., Patel, V.L.: Heuristic evaluation of infusion pumps: implications for patient safety in Intensive Care Units. International journal of medical informatics 73(11), 771-779 (2004)

21. Holzinger, A., Schlögl, M., Peischl, B., Debevc, M.: Optimization of a Handwriting Recognition Algorithm for a Mobile Enterprise Health Information System on the Basis of Real-Life Usability Research. In: Obaidat, M.S., Tsihrintzis, G.A., Filipe, J. (eds.) eBusiness and Telecommunications, Communications in Computer and Information Science, CCIS 222, vol. 222, pp. 97-111. Springer, Berlin Heidelberg (2012)

22. Calero Valdez, A., Ziefle, M., Horstmann, A., Herding, D., Schroeder, U.: Effects of Aging and Domain Knowledge on Usability in Small Screen Devices for Diabetes Patients. In: Holzinger, A., Miesenberger, K. (eds.) HCI and Usability for e-Inclusion. LNCS 5889, pp. 366-386. Springer, Berlin, Heidelberg, New York (2009)

23. Ziefle, M., Klack, L., Wilkowska, W., Holzinger, A.: Acceptance of Telemedical Treatments - A Medical Professional Point of View. In: Yamamoto, S. (ed.) Human Interface and the Management of Information. Information and Interaction for Health, Safety, Mobility and Complex Environments, Lecture Notes in Computer Science LNCS 8017, pp. 325-334. Springer Berlin Heidelberg (2013)

24. Ziefle, M., Rocker, C.: Human-centered design of e-health technologies: concepts, methods and applications. IGI Global (2011)

25. Richter, J.G., Nixdorf, M., Becker, A., Koch, T., Monser, R., Schneider, M.: Mobile Computing instead of paper based documentation in German Rheumatology. In: Mobile Business, 2006. ICMB'06. International Conference on, pp. 28-28. IEEE, (2006)

26. Brewster, S., Lumsden, J., Bell, M., Hall, M., Tasker, S.: Multimodal'eyes-free'interaction techniques for wearable devices. In: Proceedings of the SIGCHI conference on Human factors in computing systems, pp. 473-480. ACM, (2003)

27. Lam, H., Kirkpatrick, A.E., Dill, J., Atkins, M.S.: Effective display of medical laboratory report results on small screens: Evaluation of linear and hierarchical displays. International Journal of Human-Computer Interaction 21(1), 73-89 (2006)

28. Arhippainen, L., Tähti, M.: Empirical evaluation of user experience in two adaptive mobile application prototypes. In: Proceedings of the 2nd international conference on mobile and ubiquitous multimedia, pp. 27-34. (2003)

29. Väätäjä, H., Roto, V.: Mobile questionnaires for user experience evaluation. In: CHI'10 Extended Abstracts on Human Factors in Computing Systems, pp. 3361-3366. ACM, (2010)

30. Prgomet, M., Georgiou, A., Westbrook, J.I.: The Impact of Mobile Handheld Technology on Hospital Physicians' Work Practices and Patient Care: A Systematic Review. J. Am. Med. Inf. Assoc. 16(6), 792-801 (2009)

31. Holzinger, A., Hoeller, M., Bloice, M., Urlesberger, B.: Typical Problems with developing mobile applications for health care: Some lessons learned from developing user-centered mobile applications in a hospital environment. In: International Conference on E-Business (ICE-B 2008), pp. 235-240. INSTICC, (2008)

32. Charlotte, T., Sheelagh, C.: Evaluating the deployment of a mobile technology in a hospital ward. In: Proceedings of the 2008 ACM conference on Computer supported cooperative work, pp. 205-214. ACM, (2008) 
33. Jen, W.-Y., Chao, C.-C., Hung, M.-C., Li, Y.-C., Chi, Y.P.: Mobile information and communication in the hospital outpatient service. International Journal of Medical Informatics 76(8), 565-574 (2007)

34. Skov, M.B., Hoegh, R.T.: Supporting information access in a hospital ward by a contextaware mobile electronic patient record. Personal and Ubiquitous Computing 10(4), 205$214(2006)$

35. Geiger, A.M., Greene, S.M., Pardee III, R.E., Hart, G., Herrinton, L.J., Macedo, A.M., Rolnick, S., Harris, E.L., Barton, M.B., Elmore, J.G.: A computerized system to facilitate medical record abstraction in cancer research (United States). Cancer Causes \& Control 14(5), 469-476 (2003)

36. Hsieh, S.-H., Hou, I.-C., Cheng, P.-H., Tan, C.-T., Shen, P.-C., Hsu, K.-P., Hsieh, S.-L., Lai, F.: Design and implementation of web-based mobile electronic medication administration record. Journal of medical systems 34(5), 947-958 (2010)

37. Holzinger, A., Softic, S., Stickel, C., Ebner, M., Debevc, M.: Intuitive E-Teaching by Using Combined HCI Devices: Experiences with Wiimote Applications. In: Stephanidis, C. (ed.) Universal Access in Human-Computer Interaction. Applications and Services, Lecture Notes in Computer Science, LNCS 5616, pp. 44-52. Springer Berlin Heidelberg (2009)

38. Holzinger, A.: Finger Instead of Mouse: Touch Screens as a means of enhancing Universal Access. In: Carbonell, N., Stephanidis, C. (eds.) Universal Access: Theoretical Perspectives, Practice and Experience, Lecture Notes in Computer Science (LNCS 2615) pp. 387-397. Springer, Berlin, Heidelberg, New York (2003)

39. Siek, K.A., Rogers, Y., Connelly, K.H.: Fat finger worries: How older and younger users physically interact with PDAs. Human-Computer Interaction - Interact 2005, Proceedings, vol. 3585, pp. 267-280. Springer-Verlag Berlin, Berlin (2005)

40. Holzinger, A., Höller, M., Schedlbauer, M., Urlesberger, B.: An Investigation of Finger versus Stylus Input in Medical Scenarios. In: ITI 2008: 30th International Conference on Information Technology Interfaces, pp. 433-438. IEEE, (2008)

41. Weippl, E., Holzinger, A., Tjoa, A.M.: Security aspects of ubiquitous computing in health care. Springer Elektrotechnik \& Informationstechnik, e\&i 123(4), 156-162 (2006)

42. Kieseberg, P., Hobel, H., Schrittwieser, S., Weippl, E., Holzinger, A.: Protecting Anonymity in the Data-Driven Medical Sciences. In: Holzinger, A., Jurisica, I. (eds.) Interactive Knowledge Discovery and Data Mining: State-of-the-Art and Future Challenges in Biomedical Informatics, Springer Lecture Notes in Computer Science LNCS 8401, pp. 303-318. Springer, Berlin, Heidelberg (2014) 